\title{
Hedendaagse kuns en die Christelike Godsdiens
}

Het die hedendaagse kunstenaar nog iets te sî aan sy medemens? Het hy nog 'n boodskap aan die Westerling? Sê hy nog iets aan die Christen? Hy praat nog maar sy sprake is bloot 'n skreeu in die lee ruimte. Ons hoor daarin die roep ...Berge val op ons. heuwels hedek ons!" In sy oomblikke van optimisme mag dit nog wees: .. Iat ons eet en drink en vrolik wees, want more sterf ons!" En dan is die kunstenaur besig met sy ek, sy gebreekte ek. Sy ek is egter nie meer 'n redelik. sedelik en godsdienstige wese nie. Nee. hy het in dier geword wat kan praat en sy ek is blote liggaamlikheid. Sy eie liggaam veral in sy seksualiteit. hou hom tot walgens toe besig. terwyl tussendeur die doodsangs sy naakte liggaamlikheid steeds bedreig. Die kunstenaar sien homself en sy medemens in 'n gebreekte werklikheid as gebreekle wesens. En hy raas, hy skreeu. hy vloek teen wie'? teen wat? Hy weet nie maar hy weet dit dat hy bedreig word deur 'n verwarde en bose werklikheid en hy is daarteen magteloos. Hy is die onskuldige slagoffer in die irrasionele dreiging. Skuldbesef het hy nie; hy weet net dat hy bedreig word.

Dit is ' $n$ lang geskiedenis wat hieragter $k$. Dit het begin by die Paradys. Die ongeskonde mens, geskape na die beeld van (jod. die ongeskonde mens in 'n ongeskonde skepping. want $\mathrm{G}(\mathrm{wl}$ het alles goed geskape. het die opdrag ontvang om die skepping te bewerk en te bewaak Daarmee is aan hom $n$ kultuurtaak gegee. Dit beteken dat hy objektief die gegewens in die skepping moes ontgin mar dat hy hom in sy kultuurtaak ook subjektief op homself moes rig. Hoe dit betrekking sou hè op die mens self voor die sondeval is nie. met die oog op die onderwerp, ter sake nie. Wat wel van belang is. is dat God die mens na die sondeval nie geheel loslaat nie. En dit geld nie alleen die gelowige sondaar nie maar selfs die ongelowige. Dit mag algemene genade of die uitstel van die oordeel van God genoem word. maar die kwaad het tog nie in sy uiterste konsekwensies deurgewerk en van die mens 'n volslae duiwel gemaak nie. Selfs in die gevalle mens het sprankies van die beeld van God nagelewe. Hy het nog 'n sckere idealisme behou en het nog die goeie en harmoniuse in algeneen menslike sin nagestrewe.

Die kultuurtaak is nie nagelaat nie. Merkwaardig is dit dat ons van Jubal uit die geslag van Kain lees: .Hy was die vader van alnal wat op siters en fluite speel". (Gen. 4:21). So was Tubal.Kain ook uit hierdie afvallige geslag. 'n smid wat allerhande koper- en ysterinstrumente gemaak het. Dit lyk asof die Here aan die ongelowige en heiden meer talente in die beoefening van die kuns gegee het as aan die gelowige. Deur die eeue heen het dit tot 'n groot mate so gebly. Tegniese ontwikkeling en natuurwetenskaplike vooruitgang kom tot in ons tyl meesal uit die kringe van die ongelowiges. Ook die kuns ontwikkel hoofsaaklik in heidense kringe. Die spoorslag tot kunsbeoefening het in die ou tyd wel gewoonlik gespruit uit dic heidense afgorlediens. 
Tog was dit in dic Midde-Ooste, in klassicke tye in Griekeland en Rome. die heiden wat presteer as kultuurbouer.

Merkwaardig dat die kunsbeoefening eintlik in insinking belewe. sedert die Christelike kerk beslag kry in die wêreld. Die Roomse Kerk $\hat{l} \hat{e}$ in die Middeleeue sy hand op die kunstenaar en sy werk en beheers dit so dat dit tot 'n groot mate tot stagnasie gelei het. Dit word vandag nog die kerk verwyt dat hy die kunstenaar en kunsbeoefening op Roomse wyse aan bande wil lê.

Toe kom die Renaissance. Dit was 'n direkte gevolg van die herontdekking van die klassieke tydvak van Griekeland en Rome. Oor die donker Middeleeue heen gryp die kunstenaars terug na die voorbeeld van die klassieke. En dit plaas ons binne die moderne tyd. By die Renaissance begin die moderne kuns.

Voordat ons die ontwikkeling van die kuns verder volg, is dit nodig on die begrippe kuns en skoonheid wat sedert die Renaissance as maatstaf dien van nader besien.

C. Rijnsdorp formuleer dit kortliks soos volg: ..Men wijst er dan op die kunst met kumnen verband houdt. en ook, dat onder het begrip kunst niet alleen het kunstvermogen valt, maar ook de som van alle kumstwerken". ${ }^{1}$

Hierdie kundigheid word aangewend i.v.m. die skoonheid. Die begrip skoonheid het nog altyd, tot onlangs, gestaan i.v.m. 'n bepaalde wêreldbeeld. ..Het sleutelwoord van dat wereldbeeld was harmonic. De harmonie er wel niet in werkelijkheid, maar men streefde ernaar de dingen zo te denken. dat men zc met elkaar in harmonie kon brengen. De idee der harmonie sweefde boven de gekende wereld als ideaal": Hierdie opmerkinge roep in gedagte die opvatting van Dr. A. Kuyper dat die kunstenaar profeties teruggryp na in vergange Paradysweelde en vooruitsien na die komende heerlikheid.

Wat op ander terreine, bv. staatkundig en maatskaplik, nie vermag word nie. naamlik om harmonie of vrede te bewerkstellig. moet in die kuns tog wel bereikbaar wees. In die kuns moet die droom van die harmonie werklikheid word. Hierdie droom of idealisme was die besieling van die kunstenaars vanaf die vroegste tye. Daar mag in in skildery beweeglikheid en selfs stormagtigheid wees, maar dit is georden en beheersd. Selfs in die beweeglikheid is harmonie en eenheid. Rangskikking en dieplewerking is van die uiterste belang. So was dit ook steads tot onlangs met musiek en die woordkuns. Harmonie was die wesenstrek van elke kunsuiting.

Daarom kon ook die (hristen die kunswerk onbevange geniet. $\mathrm{Hy}$ glo in 'n Skepper wat orde en harmonie geskape het. En ek dink dat ons maar gerus met kuyper herın iets profeties mag sien (Totius noen ook die digter in siener)." Hierdie kunsbeskouing wat deur die Renaissance van die ou klassieke geerf is. het immers ook invloede ondergaan vanwee die (hristelike bewussyn van die Renaissance kunstenaars. In die Bybel kry ons wel geen kunsteoriec nie maar die Bybel verwerp nie die werke van skoonhcid deur heidene voortgebring nie. Dit word alleen verwerp indien dit in diens van die afgodiese praktyke 
staan. Salomo huur bv. ambagsmanne van koning Hiram on te help met die tempelbou. Paulus sien nie alleen die Romeinse owerheid van sy tyd as 'n dienaar van God nie, maar verklaar selfs van die heidene dat ..wat van God geken kan word, in hulle openbaar is. want God het dit aan hulle geopenbaar" (Rom. 1:19).

In die verband verklaar Rijnsdorp van die Renaissancetydperk: .Weliswaar bleven die antieke bouwmeesters, beeldhouwers en schrijvers de groote voorbeelden, maar men was zich toch ook van eigen scheppingskracht zeer bewust. Ik kom nu tot de verhouding van renaissance en christendom. Twaalf eeuwen christelijke geloofspraktijk, hoe gebrekkig ook, waren niet spoorloos aan de ltaliaanse samenleving voorbijgegaan. Wanneer ook in de Hellenistische sameleving de stoicyn. persoonlikheidsvorming nastreefde. dan had dit toch een andere, ik zou bijna zeggen fletsere kleur dan het renaissance persoonlijkheidsideaal. Het evangelie had de onvergelijhlike betekenis van de afzonderlijke mens in het licht gesteld". 'Hierdie opvatting. verkladr hy voots, het so 'n ingang in die Westerse wèreld gehad dat dit vandag nog een van die geloofsartikels van die vrye Weste is, al hang hulle nie meer die christelike geloof aan nie.

Die kuns het ook nie geheel met die kerk van Rome gebreek nic. Die kerk was ' $n$ belangrike opdraggewer met ' $n$ groot verskeidenheid van onderwerpe, figure ens. vir die kunstenaar. Selfs al sou die gees van die kunstenaar heidens wees. het sy bewussyn op 'n insig berus wat aan die evangelie ontleen is. Die ideslsstiese kunsopvatting, gedra deur die begrip van harmonie, is derhalwe ten minste nie in stryd met die christelike godsdiens nie en die christelike bewussyn was ook medewerksaam in die vorming van die hierdie opvatting van die Renaissance.

Basies het dit die algemene kunsopvatting gebly tot aan die begin van ons eeu. Wat die latere Romantiek hieraan toevoeg, is eintlik alleen maar om die hart van die mens, sy gevoel. tot sy reg te laat kom. Eintlik is die gevoel op die spits gedryf, maar hulle verdienste was dat die gehele mens nou tot sy reg kom: verstand en hart. liggaam en siel. .En het selfbewustzijn van de renaissancemens wordt in de romantiek de souvereine vrijheid van het scheppend genie"."

Rijnsdorp noem dan die kunsbeskouing wat via die Renaissance en Romantiek aan ons oorlewer is .Jumanistieschristelik". Eintlik het die kunsbeskouing die Christelike leuens- en wêreldbeskouing nie aangetas nie. Dit was algemeen menslik en nie anti-christelik nic. Dic Christen kon dit onbevange geniet en deel in die kunsprodukte wat die wêreldling of humanis voortgebring het. Sedert die werke van die Renaissance-kunstenaars, soos l.eonardo da Vinci, Rafael. Michacl Angelo ens., tot die Romantiek en selfs tot by die Impressioniste is kunswerke voortgebring waarin in mens iets kon sien van die werke van God. Dink bv. aan die Godverheerlikende musick wat in humanis soos Beethoven gekomponeer het.

In die twintigste eeu kom daar in hierdie kunsbeskouing 'n radikale verandering. Die nuwe kunsbeskouing is "n prokluk van die nuwe tyd. (Om te begryp watler magte hier aan die werk is. wil ch in kort 
oorsig van die ontwikkeling van die beeldende kunste gedurende die laaste jare aan $u$ bied. In die oorsig sluit ek aan by in insiggewende artikel van die bekende Franse kunskritikus, René Huyghe in ... arouse Encyclopedia of Modern Art".

Uit die oorsig tree dujdelik aan die lig hoe die konkrete kunsbeskouing afgebreek word en alleen onbestendige vloeibaarheid as resultaat het. Eintlik het ons tyd geen kunsbeskouing nie. behalwe dat gestrewe word na die nuwere en veranderlike teenoor die ouere en kon. stante. (jeen beginsel of norm, hetsy esteties, eties of religieus, word crken nie.

Elke beskawing. sê Huyghe, is 'n poging om die samelewing so te orden dat dit beter begryp kan word. In die loop van sy ontwikkeling bereik ' $n$ beskawing 'n bepaalde orde wat uitgedruk word in in sisteen van paslike lewensvorme wat die innerlike gesindhede van so in be. skawing tot uiting bring. Dit is nodig dat vorm en inhoud mekaar dek. Wanneer bloot terwille van die vorm aan die oorlewering vasgehou word, raak in beskawing onvrugbaar. Dit werk verstarring of stagnasie in die hand. Aan die ander kant bestaan die moontlikheid van reaksie wat daartoe kan lei dat 'n hele beskawing oorboord gegooi word. Nie alleen nuwe uildrukkingsvorme word gesoek nie. maar ook die innerlike gesindhede. die inhoud van die uitdrukkingsvorme, word verwerp. Dan word ou waarhede nie alleen op 'n nuwe en prikkelende manier gesê nie. maar die waarhede self gaan verlore.

Teen die helfte van die negentiende eeu kry ons só 'n reaksie teen oorgelewerde vorme. Veral sedert die Romantisisme en die Impressionisme word daar gegis en gesoek na nuwe uitdrukkingsvorme. Insiggewend is dat René Huyghe verklaar dat hier groter sake op die spel is as wat dit oppervlakkig lyk. ..Dit wat onder ons ö̈ verkrummel en verdwyn in die verwarring wat allerwee aangevoel word as 'n groeiende en oorweldigende krisis, is niks anders as die beskawing self nie". sê hy." Hiertoe dra tegniese. wetenskaplike en sosiale. politieke en godsdienstige ontwikkelinge in die Westerse werreld grootliks by. Kultuur wat altyd in geestelike weerspie bewus of onbewus aangewend om sistematies af te breek. Die voort. skreiding van hierdie afbrekingsproses kan duidelik in die ontwikkelling van die kuns waargeneem word.

Reeds in die agtiende eeu het in Wes-Europa in belangstelling vir die Ooste en veral vir die Chinese kultuurerfenis ontstaan. In die negentiende eeu word dit 'n onversadigbare sug na die eksotiese Oosterse. Dit is die dageraad van die Orientalisme in die kuns. Romantiese en Impressionistiese skilders word onk geinspireer Jeur Indiese en Japanese invloeal. Selfs die opgrawings in Mesopotamie en Egipte laat sy spore na in die werk van Westerse kunstenaars. Die invloed van die klassieke Romeine en (iricke, wat die kunstenaars van die Renaissancetydperk so sterk beinvloed het. word meer en meer afgeskud. Die neiging hom na vore om primitief en ..barbaars" te skilder.

..Denkende mense kom so le staan op die drumpel van in nuuc fase in die ontwikkeling van hul kultuur. Hulle erken nie alleen die 
waarde van die vreende beskawinge wat geen verband met hulle eie het nie, maar gee selfs voorkeur daaraan. Hulle aanvaar Jean Jacques Rousseau se stelling dat kuns meer „outentiek" is wanneer dit die minste onderwerp was aan die suiweringsproses van die kultuur"?

Sedert die begin van die twintigste eeu verskyn die invloed van die Negerkuns uit Afrika ook. Danksy die kunswerke van Matisse en sy volgelinge soos Vlaminck. Derain, en Picasso vind hierdie Negergeinspireerde werke spoedig hulle tuiste by belangrike versamelaars.

So word die sg. primitiewe of argatse kuns spoedig verkies bo die tradisioneel Westerse. Die kuns word teruggebring tot sy veronderstelde oorspronklike suiwerheid voordai dit ..besmet" is met die glans van die beskawing. Nie alleen die kuns van die primitiewe mense nie, maar selfs van die kind of kranksinnige word die bron van die inspirasie. Die primitiewe, kinderlike of onvolwassene word sinoniem met die suiwere in die kuns. Aan die ander kant is gekultiveerd eintlik sinoniem met besmet en verword. Alles wat elementèr, ongeformuleerd is, alles gesimboliseer deur die brute natuur, is van waarde beskou. Kwaliteit word verwerp ten gunste van intensiteit. ..Soos Pousin die kunstenaar tipeer wat sy inspirasie uit sy intellek put, so plaas 'n molerne kunstenaar soos Vlaminck sy swaartepunt veel laer by die buik of die heupe of die geslagsorgane. Die skokkende en gewelddadige kom nou in aanvraag. Deur die uitwerking van die kleed van die beskawing en kultuur af te skud, begeer hulle on nuutgebore en onskuldig terug te keer tot die oorspronklike impuls"."

in Soortgelyke teruggang vind plaas t.o.v. die keuse van materiaal. Marmer maak plek vir afvalyster en gruis, as materiaal vir die beeldhouer.

„Die gevoel van skaamte, sonss van haat, vir wat ons was en nog is deur oorerwing, is 'n duidelike bewys van die strewe om opnuut te begin en ontslae te wees van alle struikelblokke wat die, tot nogtoe. onbepaalbare wedergeboorte verhinder"."

Wat die kunstenaars en denkers nou in die verband ernstig begin besig hou, is die vraag: wat is kuns?' Sommige sien dit as die ekspres. siewe impuls: andere as die plastiese konstruksie wat die resultaat van die impuls is. Eersgenoemde sien dan die kuns as " $n$ middel om die vasstaande en outentieke realiteit van die mens bloot te lê. Maar waarin bestaan die outentieke realiteit van die mens? Soms word dit gesien as sy organiese natuur, soms as sy temperament. Veral nadat die sielkunde hulle teorie t.o.v. die onderbewuste geformuleer het, het die surrealisme in die kuns ontstaan en vinnig begin veld wen. (liteindelik ontwikkel dit dan tot die informele kuns wat beide vorm en beeld verwerp en sigself in die lewensstroom werp en alleen die oerdrifte en vibrasies probeer weergec.

Benewens hulle wat die kuns sien as die projeksie van in ekspressiewe impuls. was daar kunstenaars wat alle beeldende kunste sien as vorme en kleure wat in in bepaalde orde gerangskik is. Hulle realuscer kuns dan tot 'n samevoeging van lyne en kleurvlakhe. Die Franse skilder Cezanne het deur sy rekonstruksis: van die natur tot basiese vorme en 
kleurvlakke 'n baie groot invloed in: die rigting uitgeoefen. Dit lei tot die kubisme en uiteindelik tot die abstrakie kuns wat alleen dic wette van harmonie en selfdissipline in ag ncem en die natuur of werklikheid geheel verontagsaam.

Huyghe verklaar: .. Werklikheid en redenlikheid was die pilare van 'n tempel wat gebou is deur voortuurende inspanning sedert die Grieke lot die Romeine; vanaf die Rencissarce tol die Neo-klassisisme. Die twintigste eeu het dit wreedaardig ontwortel en vernietig"."

Sedert die impressionisme het die kuns vinnig wegbeweeg vanaf die werklikheid. André Breton som diit it 1955 soos volg op (aangehaal deur Huyghe)": .. Ons het lank gestaar na die bewegende punt vanwaar ons sien hoe die dinge vervaag to'd:t dit geheel verdwyn. Alleen dan word die gees van die dinge blootrele. (Om die band wat ons bind deur te sny - beide van gewoonte en scrtiment - en so te kom tot die banale waarneming".

Skilderkuns raak nou suiwer en alleen gebind aan kleur en lyn. Dit bereik die absolute. die suiwere hiths. Die vee alles weg on tot leeglieid te kom. Elke spoor van tracisis moet geheel uitgewis word. Die voorwerp het geheel verdwyn en skiderkuns word bloot in abstrakte impuls.

Soos hierbo aangetoon het verai die sielkundige ontwikkeling van die begrippe i.v.m. die onderbewusis van die mens veel bygedra tot die verwerping van die rasionele er, $:$ lfs die wil van die mens by die beoefening van die kuns. ..Idees. lonira, orde. Waarheid (met 'n hoofletter W). rede - ons sal dit alle; ar sgee aan die ..niksheid" van die dood" (Huyghe)." Nie alleen red incieid nie. mar selfs die bewustheid word uitgeban. Alleen onrede!ke en onbewuste willekeur bly onr. $\mathrm{Na}$ die tweele wêreldoorlog probut tie s.g. abstrakte ekspressionisme of informele kuns om die heperkinse van die verbeclding verby te strewe -.. strepe en verfspatsels die doek is die poging om uitJrukking te gee aan oer-emosies. tiic bewuste kontrole van die wil of rede word verwerp.

..Point Zero" is bereik. ..On. ien die risiko - die risiko van absurditeit. (Ons aanvaar die veraniwnordelikheid van die risiko. Ons. diere wat kan praat. is die tolke van die stomme wêreld". ${ }^{13}$

Indien die molerne kunsrigtira glo dat hulle hulself geisoleer het in wat hulle ...suiwerheid" of ..pretensieloosheid"noem. bevry van elke uitwendige konvensie. bedrieg hulic nulself, beweer Huyghe (p. 250)).

Deur te kyk na hulle werke sien ons hulle siel. 'n Kunstenaar kan nic anders as om sy eie innerlike en sy eie tyd te weerspieël nie. Die kunstenaar wend steeds 'n poging aail om deur te dring tot die kragte of moliewe wat agter die uiterlike en sigbure dinge lê. Die surrealiste

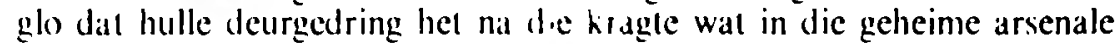
van die onderbewussyn opgesluit $k, r, n$ die surrealiteit volg 'n geslag. bv. die Neolummanistiese skitders. w'lt die lema van leegheid uithou. So beg̣in die leegheid vorm aanneen as dic angs van die eensaamheid. verlatenheid in namelose ellende. ... ilsorwee sien ons die mens geteken as verlore in in vreemkle werreld warin die mense vreemdelinge vir 
mekaar is". ${ }^{13}$ Van 'n beeldhouwerk van Giacomelti sê 'n kritikus bv.: ..Wat bly oor van die mens? 'n Figuur op die rand van die niksheid. Hierdie beeldhouwerk van die leegheid grens aan die absurditeit. Dit is die beeldhouwerk van die wanhoop"." "

Nou verskyn die tenla van die hindernis of die grens. Diepte verdwyn uit die skiklerye. (jeen opening of uitsig word gelaat nie. Die skilder laat ons vaskyk teen in ondeurdringbare muur. leegheid, vrugteloosheid, eensaamheid, ellende - alles loop ten slotte uit op vrees. Niks word meer begryp rie. behalwe dat alles bedreig word. Onafwendbaar verskyn die monster weer in die kuns. Die monster is vir eeue teruggedring deur die humanisme, maar het opgestaan, want die humanisme het gefaal en die men; het ook elke ander houvas verloor. Allerweë, in elke denkbare vorm gryns die monster uit skilderye --- selfs rotse en plante dreig soos afgryslike monsters.

Hou die beoefening van die kunsrigtings van ons tyd esteties die gevaar van kunssinnige selfmoord in, dan is dit ideologies nog veel gevaarliker. Die kunstenaar hanteer 'n wapen wat subtiel en geraffineerd gerig is op die mens se hart. Bloot deur te breek met alles wat in die verlede as goed en edel beskou is, wil die kunstenaar daarmee aan die Westerling sê: ..Jou erfenis is waardeloos. Dit is verwerplik. Jy behoort jou daarvoor te skaam". Selís 'n kunskritikus soos Huyghe verbind die strewe van die Weste on cie Oosterse en sg. „ongerepte" barbaarse te verheerlik, met die liberale siagspreuke wat ons so goed ken. Hy skryf .Dieselfde gees word noodwerdig weerspieël in die politick. Europa en die blanke rasse in die algeme $n$ is a angegryp deur ' $n$ soort skuldkompleks teenoor Jie mense aan $w$ ' vroeer bloot gedink is as wesens on te corheers. Hierdie kompleks ne! in sommige opsigte 'n soort rusteloos masoshisme" geword".

Tereg beweer Huyghe dat hier groter dinge op die spel is as bloot die kuns. Ons beskawing is hier op die spel. En nie alleen die beskawing nie. Ook en veral die christendom word in sy wese aangedurf. Die kunstenaar gebruik sy talent on dit wat vir die Christen onwankelbaar en heilig is, eers met $n$ vraagteken te laat besien. Spoedig worl die vraagteken vervang deur openlike bespotting.

In 'n bespreking van die werke van die skilder Wols skryf Platschek o.a. in die Nederlandse tydskrif: „Nieuwe Figuratieve Kunst”: ,.een nulpunt waardoor niet alleen de schilderkunst naar ook de kenmerken van de werkelijkheid overbocig worden gemaakt. Voor Wols is dit punt het centrum van zijn bestaan en schilderkunst is voor hem de belicham. ing van de twijfel. Hierdoor stond niet alleen de schilderkunst op het spel, maar meer dan dat: de symbolen der werkelijkheid en de elementen der eigen existentie. Dat desondanks deze schilderijen tot stand kwamen is in elk geval een daad van zeitbehoud" (aangehaal deur Rookmaaker)."

Selfbehoud? Wat 'n vreugdelose selfbehoud! Bly daar in 'n skil. dery nog iets oor wat leesbaar is, dan word selfs die leesbaarheid daarvan problematies. Agter alles wat werklik is, word die groot vraagteken geplaas. Die kunstenaar se sg. werklikheid wat hy aan ons voorhou is volslae irrasioneel. Elkeen kan na eic willekeur 'n eic sin daarin lees 
of geen sin daarin vind nie. Hierdie skiklerkuns gaan uil van die vernieligde wêreldbeeld - alle gevestigde waardes hel verdwyn. Die wèreld het naamloos en daarom waardeloos geword. Norme en waardes is vervang deur in grenslose relatiwiteit. Llke poging on sin en betekenis in die wêreld tc ontllek. is sinloos. Dit is die taal van Wols en sy geesgenote. Rookmaaker haal bv. ook die volgende uitspraak van René Iluyghe in Kroniek van Kunst en Kultuur 1947 p. 47 aan: waar Huyghe sê dat die moderne kuns gekarakteriseer kan word met die woorde: ..()ns voel ons sweef in "n lee ruimte"."it

Volgens Rookmaker het die surrealisme die geykte wêreldbeeld oorgelewer aan die irrasionele spel deur skynbare werklike gestaltes. Dit word met opset weergegee deur die bekende uitheeldingswyse op in vreemde. toevallige en onwerklike manier te verbind en saam te voeg. Daarmee word aan ons in spieel voorgehou met die vraag: ..Dit lyk vir jou wel gek. maar is dit eintlik nie net so gek as die bekende werklikheid nie. En waarom kan dit nie die normale wees en jou opvatting die abnormale nie?"1i

So word gewone bestaanvorme in die werklikheid. so word tradisionele beginsels. norme en wardes vernielig. ..Hoeveel angst. hoeveel vlucht hoeveel hat er in vele zgn. non-figuratieve werken is neergelegd. wie zal het ons zeggen? Hier word schilderkunstig gevloekt. (inostiesch wordl $(i x)$ verweten dat Hy een rolle wireld maakte of neen. dat kan ook niet meer. want (jod is er niet "."

Rijnsdorp verklaar in die verband: .. De kunst is de vaste grondslag. de statische basis van de renaissance kwijtgeraakt. Ze zweeft in eei vacuum. De werkelijkheid heeft zich in het recente verleden zo onbetrouwbaar. verraderlijk en absurd getoont. dat men het geloof in haar heeft verloren. Ze bied ook geen waarborg van bestendigheid meer. Bovendien ze heeft duisend gezichten. Wat moet de schilder afbeelden. wat moet de beeldhouwer vormen:? Men experimenteert. of knoeit als kinderen. ${ }^{1: 4}$

Eintlik kan ons ook op die beeldende kunste toepas wat Rijnsdorp beweer van die literatuur: ..7e is, on die Apocalyps te citeren. een mond die groten dingen spreckt".":"

Die Renaissance se kunsbeskoung is in likwidasie. Die Christelike opvattings het vir alle praktiese doeleindes opgehou om in faktor van belang te wees in die kulturele lewe. Met die Romantisisme is afgedaan as in idealistiese negentiende eeuse verskynsel. ..de fondamenten onder de kunstvisie zijn weggebroken. zolat het hele gebouw der kunst op instorten staat. ir is een mondiale heroricutering aan de gang. Waarbij het christendon geen rol meer speelt en de postchristelijke mens al experimenterend heenleeft naar een situatie. waarin hij misschien op waarden zal stuiten. die de moeite van het proberen lonen. Hoe de eventuele nieuwe waarden er uit zullen zienen, weet niemand, maar ze zullen onvermijdelijk religieuse trekken vertonen. Men moet aan iets of iemand geloven en daarvan vrij getuignis kunnen afleggen"."1

Wat gaan die anker van die mensdom wees"' Wie sy inspirasie? Sien ons ook hier hoe die loneel reggeskuif word vir die aanbidding van die dier uil die see? 
In die hedendaagse kunsbeskouing sien ons iets van die angskreet van dic apokaliptiese mens: ,.Berge val op ons!"”: Ons sien wat deur die Bybel die mens van die wetteloosheid genoem word, wat hom verhef teen al wat God of voorwerp van verering genoem word ( 2 Thess. 2:4). Dit is duidelik dat die nuwe irrasionele wêreldbeeld opkom uit 'n nihilisme, wat meen dat hulle gcheel met God afgereken het.

Soms word gepoog om 'n soort mite op te bou, 'n irrasionele mite. verklaar Rookmaaker. ${ }^{+3}$ Maar die christendom het deur sy evangelieverkondiging alle mite-vorming reeds te vér ontmasker en aan die kaak gestel, sodat dit alleen maar 'n leë skreeu in die leë ruimte bly.

Kyk 'n mens ernstig na die beeldende kunste. dan kan jy nie daar. oor lag nie. Jy vra alleen maar: ., Wagter hoe laat is dit in die nag?

M. J. BOOYENS.

\section{VERWYSINGS:}

1. C. Rijnsdorp: „Aan de Driesprong”. (Bosch \& Keuning.) p. 47.

2. C. Rijnsdorp: ..Aan de Driesprong". (Bowh \& Keuning.) p. 47.

3. P. J. Nienaber: Totius - Digler en Profect. (Afrikaanse Pers Beperk. 1948) p. 229.

4. C. Rijnsdorp p. 48

5. C. Rijnsdorp p. 49.

6. Larousse Encyclopedia of Modern Art - General Editor René Huyghe p. 243

7.

8.

9.

10.

11.

12.

13.

14.

15. Dr. H. R. Rookmaaker: Kunst en Amusement. (J. H. Kok N. V.. Kampen 1962) p. 15.

16.

17.

18.

19. C. Rijnsdorp. p. 51 .

20. $, \quad, \quad$ p. 52 .

21. ., , p. 53.

22. Rookmaaker, p. 18.

23. $\quad$ p. 19.

Frkenning: Die hoofsaak van die gegewens in bostaande stuk vervat is onllech aan 'n praatjie wat in opdrag van die $S$. $A$. U. K uitgesaai is. p. 244.

p. 244

p. 244 .

p. 246

p. 248

p. 248

p. 250

p. 250 . 